\title{
HOW TELEMEDICINE HASS CHANGED SURGICAL PRACTICE IN COVID PANDEMIC
}

\section{Praveen Kumar*}

Farhanul Huda

\section{Somprakas Basu} Department of General Surgery, All India Institute of Medical Sciences
Rishikesh India. *Corresponding Author

Department of General Surgery, All India Institute of Medical Sciences Rishikesh India.

Department of General Surgery, All India Institute of Medical Sciences Rishikesh India.

\section{ABSTRACT Background-The history of telemedicine parallels the history of communication and information} technologies. With the advancement in information and communication technologies, telemedicine has also progressed. Still, it could not gain a respectable place in the healthcare delivery system due to lack of clear guidelines, lack of multidisciplinary approach to patient management, onerous privacy regulations, lack of reimbursement, lack of human touch in teleconsultations, and lack of integration with the national health system. There is a need to promote telemedicine services by looking into the current framework and bringing necessary changes to ease the delivery of services. Also, proper training of health care professionals about digital communication to improve patient outcome, and the introduction of telemedicine in medical education so that medical students do not suffer in the present scenario of COVID-19.

Methods- We searched MEDLINE, Embase, PubMed, and PubMed Central. We used free-text terms and MeSH terms such as telemedicine, telemedicine, and COVID 19 pandemic, telemedicine and medical education, telemedicine pitfalls. Data regarding the guidelines of telemedicine and waivers during the pandemic, the current status of telemedicine in the healthcare delivery system, and its promotion during the epidemic were extracted. Finally, 43 articles were found suitable to be considered for writing this evidence-based review.

Results-Telemedicine has proven to be an important tool to reduce the risk of transmission of COVID 19 without hampering patient care,medical education and research. With relaxation of existing guidelines in most of the countries and training of healthcare professionals to introduce digital empathy it can be closer to a usual patient-provider encounter.

Conclusion-Telemedicine cannot replace regular face to face patient-provider encounters, but it can be helpful, especially during the times of pandemics as happening during current circumstances. It should be included in the health care delivery infrastructure with all guidelines and legality to help the existing system during normal conditions and take over in need of time.

\section{KEYWORDS : Telemedicine; COVID 19; healthcare;viral transmission;surgery}

\section{INTRODUCTION:}

Pandemic poses severe challenges to healthcare as it is happening in the current COVID-19 pandemic across the world. The focus of hospitals and healthcare. systems tends to be directed preferentially on COVID-19 cases and thus limit our ability to tackle seriously ill and uninfected cases suffering from other chronic conditions such as hypertension, diabetes, mental health, and substance abuse ${ }^{[1]}$. COVID-19 is transmitted primarily by aerosolized droplets generated during coughing, sneezing, talking or breathing, or direct or indirect contact transmission both amongst the patients and health care workers ${ }^{[2]}$. The maximum number of cases in China was due to hospital-related transmissions ${ }^{[3]}$. Healthcare facilities have shifted attention to alternatives to avoid face to face contact between healthcare workers and the patients ${ }^{[4]}$. Telemedicine (TM), which is included as part of the digital health systems of several countries, seems to be the answer to the above problem ${ }^{[5]}$. TM can ensure that individuals with low-risk COVID and chronic conditions without complications and follow-up cases do not burden already limited resources while ensuring that they seriously ill receive appropriate triage and treatment ${ }^{[1]}$. It has proven its importance in previous outbreaks of SARS-COV (severe acute respiratory syndrome-associated coronavirus) and MERSCOV (middle east respiratory syndrome coronavirus), Ebola, and Zika viruses ${ }^{[6]}$.

WHO has defined TM as "Delivery of healthcare services, when the distance is a critical factor, by all healthcare professionals using information and communication technologies for the exchange of valid information for diagnosis and prevention of disease and injuries, research and evaluation, and for continuing education of healthcare providers, all in the interest of advancing the health of individuals and their community ${ }^{117]}$. United Kingdom ${ }^{[8]}$ and the United States of America ${ }^{[9,10]}$, have promoted TM to reduce the risk of transmission of COVID-19. Still, there are several challenges to integrating it into public health for fighting COVID-19 and future outbreaks. However, the Health system of many countries lacks legislation or guidelines to authorize, integrate, and reimburse TM in their medical care delivery ${ }^{[11]}$. According to Stefano Omboni, Italy lacked the infrastructure for providing care using TM, and later on, it was promoted by telemedicine and monitoring system, National Institute of Health $^{[12]}$.

In India, on March 25, 2020, the Board of Governors, in supersession of the Medical Council of India, issued TM guidelines in their national healthcare system ${ }^{[13]}$. There is a concern about technical and clinical quality, privacy, safety, and litigation regarding $\mathrm{TM}^{[8]}$. This review represents existing guidelines and waivers, uses of TM and changes during COVID time, and its limitations during the COVID-19 pandemic.

\section{Demands Of The Covid-19 Era}

Healthcare workers providing telehealth services must have the necessary education, training, licensure, and ongoing continuing education/professional development for the safe provision of quality health services. Most states in the USA require that TM practitioners must be licensed in both states, where the practitioner is residing and where the patient is residing ${ }^{[14]}$. However, Europian guidelines restrict licensure in the state where the practitioner is living ${ }^{[15]}$. In response to COVID-19, state medical boards have started issuing waivers regarding licensure. These waivers vary from state to state. 
According to a recent letter by the American Telemedicine Association to Congress on Coronavirus IV legislation, additional funding, infrastructure development, and relaxed policies should be there in the present scenario of COVID$19^{[16]}$. In a media advisory, the American Telemedicine Association(ATA) had to waive restrictions in Telehealth for medical beneficiaries in response to COVID-19 outbreak ${ }^{[17]}$.

There should be a patient-provider relationship before starting the teleconsultation. The American Medical Association requires at least one face-to-face consult in the form of an in-person visit or real-time audio-visual encounter to establish a provider-patient relationship. Some states have introduced waivers in the provider-patient connection, but it is not acceptable to some state laws. In hospital-based telecommunication, the practitioner has to pass through a lengthy process of credentialing before starting teleconsultation. In the presence of the COVID crisis, some states permit a waiver of credentialing requirements ${ }^{[18]}$.

There are Direct Access Testing (DAT) laws in many states prohibiting laboratories from doing diagnostic tests without an order from a registered practitioner ${ }^{[19]}$. Laboratories are allowed to do tests following a teleconsultation by the practitioner following a waiver introduced by some states ${ }^{[18]}$. States have informed consent laws relating to telehealth services; the patient should be informed of specific concerns during telecommunication, and consent should be recorded. In the case of a minor, a caregiver or authorized person will do teleconsultation ${ }^{[13]}$.

According to Ryan Height Act, dispensing controlled substances via the internet without a valid prescription is prohibited ${ }^{[2]}$. A valid prescription must be issued by the practitioner who has done at least one in-person visit. In response to COVID-19, the US Drug Enforcement Administration $^{[21]}$ issued guidelines in which, during a public health emergency, registered practitioners can prescribe controlled substances without in-patient visits, provided the communication is by audio-visual, real-time, two-way interactive communication system ${ }^{[2]}$. Regarding cost-sharing obligations, the Department of Health and Human Services, Office of Inspector General issues the policy statement to notify physicians and other practitioners that they will not be subjected to administrative sanctions to reduce or waive any cost-sharing obligations ${ }^{[23]}$. Software used to support TM should be US FDA approved and should be transparent and clear to the provider ${ }^{[18]}$.

The health care provider shall ensure recordkeeping, privacy, and confidentiality. Under the Health Insurance Portability and Accountability Act(HIPAA) rules, healthcare providers may use a communication product for Telehealth if the vendor is up to HIPAA standards. Some vendors stick to HIPAA standards while others not. In a new waiver, those vendors who are not up to the HIPAA standard are also included in providing Telehealth in the COVID crisis, such as Facebook Messenger Video Chat, Google Hangouts Video, and Skype ${ }^{[24]}$. New regulatory flexibilities in Telehealth in this COVID crisis, are enabling health care providers to use commonly available platforms to deliver Telehealth. In recent trends in TM use in China, apart from apps for tracking down COVID-19 cases, the Chinese Government urgently issued notices to permit the sharing of personal data to keep an eye on suspected COVID-19 cases $^{[25]}$. In the present COVID crisis, there is also a need for cross border TM, the rights of the patient as guaranteed in the Europian TM directive $2011 / 24 / E U$, implies well in the present scenario ${ }^{[15]}$.

\section{Triaging By Telemedicine}

TM can be used in triaging patients before they reach the hospital; a questionnaire can be set regarding travel history and symptoms of the patient to know the probability of coronavirus infection and assess the kind of care needed ${ }^{[26]}$. Houston Department of Health and Human Services developed an interventional program ETHAN (Emergency Telehealth and Navigation) to reduce unnecessary ambulance transport and ED visits ${ }^{[27]}$. While dealing with cases in Wuhan, Zhang J et al. established fever clinics for therapeutic and triage strategies for cases of COVID-19 ${ }^{[28]}, \mathrm{TM}$ can be of help in these clinics for triaging and management till there is a requirement of admission. Mild cases of cough, sore throat can be managed with home isolation. Cases with fever are advised to undergo investigations like CT scan of the chest, complete blood count, and C-reactive protein. Based on these investigations, the patient is triaged and asked to undergo COVID testing and, if positive, is asked to get admitted to the designated hospital. In cases of home isolation, improper home care is discouraged ${ }^{[29]}$. Triage is done in two phases-telephone and in-office. Telephonic triage will detect potential COVID cases or contact with infected cases. In-office triage will identify patients in the incubation period who develop symptoms before the in-office visit; this type of patient will be considered unsafe for further clinical examination ${ }^{[27]}$.

\section{Telemedicine For Chronic Diseases}

Patients with chronic diseases such as COPD, diabetes, immunodeficiency, and congestive heart failure are more prone to infection with COVID -19 during in-person visits. TM advice can be followed until there are complications. It has the potential to become a useful tool to improve health outcomes, improve quality of life, access healthcare services, and reduce health costs without exposing patients with chronic disease ${ }^{[30]}$. In a video-based consultation, a doctor can virtually attend to a COPD patient. His vitals parameters, such as the respiratory rate, heart rate, and oxygen saturation, can be monitored and can be incorporated until the patient requires hospitalization. Blood sugar can be monitored in people with diabetes, and necessary investigation advised if a complication is expected. If vital parameters are found stable on video consultation in a patient with heart failure, advice can be incorporated without the need for in-person visits. In a Cochrane Database systematic review, Gerd Flodgren et al. found no difference in the management of patients with chronic conditions like cardiac disorders, sugar control in diabetics, chronic mental conditions by TM over inperson visits ${ }^{[31]}$.

\section{Telemedicine For Medical Education And Training}

Medical education's current situation is that medical schools are transforming from pedagogy by eliminating or reducing lectures using modern technology. Competency-based learning, interactive teaching, interactive problem solving, and small group discussions have been introduced for active learning.

The present scenario has prevented students from gathering in lecture halls and laboratories. Medical schools are slowly changing the entire curriculum to online formats. Online interactive seminars, online small group discussions have taken over, even clinical skill sessions have been started online. Through online platforms, medical schools can partner with the underserved and remote communities. The students under the faculty's supervision can take history and do the physical examination with the help of trained health aides. TM set up like audio-visual aids are utilized for this. Consultation skills, communication skills, and clinical reasoning skills can be taught and assessed over the virtual platform. A TM system between Gizo Hospital in the Solomon Islands and Emory University Hospital in the USA is doing this type of online clinical teaching with remote patients ${ }^{[22]}$. It has shifted the clinical environment to the home environment. However, a teacher's influence on students' overall 
professional development depends on teaching, mentoring, and role modeling, which are difficult to perform in a virtual environment. Learning by face to face patient interaction, clinical examination, and physical signs elicitation in patients are absent in a virtual platform. When examinations are conducted online, evaluation of the full practical competencies and skills is difficult. The use of a virtual case scenario is an option to simulate a clinical environment. Authentic patient experiences for medical education are a challenge in the current situation. Currently, it is difficult to predict the outcome of these changes and will need further evaluation.

The application of TM in surgery is not new. It was in 1996 when the Europian telesurgical network involved six university hospitals in four countries, to share the experience of laparoscopic surgery (adrenalectomy) for enhancing medical knowledge. This study concluded that weekly surgical teleconferences were helpful in telediagnosis of surgical cases. Since then, its application has increased for knowledge transmission, real-time discussion of complex surgical cases, and debate between participants at different sites is possible with a good quality network ${ }^{[33]}$. Progress has been made in the live demonstration of surgical cases, operations, and discussion among participants to learn new surgical techniques. Online surgical courses are being done, where students learn by telementoring ${ }^{[34]}$. Deaton et al. used telementoring while performing aortic grafting to teach and support surgeons performing it ${ }^{[35]}$.

In the present scenario, the focus has been shifted towards online learning through the conduction of webinars. Surgical training utilizes the apprenticeship model of learning and mentoring, where trainees learn by doing and experiencing ${ }^{[36]}$. Surgical training among residents is principally done by performing under supervision, which has immensely affected this COVID time. Conduction of students' webinars, online case scenario-based discussions moderated by faculty has replaced direct clinical engagement. Webinars on surgical techniques, where experts show online videos of their cases, difficulties encountered, and how to tackle complications, are helpful. This modern technology will help teach a large number of students at different places and be an excellent platform for interaction with experts ${ }^{[3]}$. Sometimes teachers, who have vast experience of classroom teaching, may face difficulty in online teaching. The European education network is organizing a series of webinars, enhancing interactivity, and going face-to-face in online teaching ${ }^{[34]}$. It will enhance the interactivity and interest of students for a successful online program

\section{Digital Empathy}

Empathy is an essential part of the provider-patient relationship. It increases patient satisfaction and eases treatment course. Modern technology tools lack empathy in communication because of a lack of emotional signals made possible in face to face communication. Accordingly, the patient's compliance and faith are affected, which has an impact on treatment outcome ${ }^{[38]}$.

The reason why telecommunications lack empathy is the online disinhibition effect ${ }^{[39]}$, which explains the lack of emotions in tele-encounters compared to in-person encounters. It is a state in which a person psychologically disconnects from their actual being when they are not facing one another, which means that a physician may be very empathetic in a face to face encounter but may not be empathetic during tele-conversations. Subconscious psychological factors play an essential role, and dynamics of professional relations alter in a digital encounter.

There should be something to introduce empathy in digital encounters, so that patient compliance is increased and ultimately has a positive impact on health outcomes. TM consultants should have empathy training, which explicitly addresses the subconscious effects of online disinhibition. Physicians can practice three simple ways of enhancing empathy in digital encounters ${ }^{[39]}$. The first thing is listening patiently and let the patient guide conversation. When a physician listens to patients peacefully, they feel respected, and this increases faith in the doctor, which will increase compliance. The second point is a follow up after appointment is over through email, text message, or interactive voice response. With this activity, patients do not feel forgotten and feel better because the show of empathy brings the provider and patient closer. The third point is to personalize communication through psychographic segmentation, identifying the psychology of the patient and tackling them accordingly, also crucial in being empathetic during telecommunication. There are two types of patients; the self achievers and the willful endurers. Former are health-oriented and need little guidance about their health. The latter type focuses on other things before their health, and these have to be handled more differently and need constant advice about their health. Consistent efforts with the endurers will win their faith and increase empathy, even without face to face interactions. TM consultants should be trained to improve the affective domain even when not face to face, and here comes the role of advanced communication skills to make a substantial TM encounter that will help in this COVID era ${ }^{[39]}$

\section{Limitations Of Telemedicine}

One of the many limitations other than those discussed above is the absence of meeting the SPIKES protocol criteria of communication skills, especially when addressing emotional and empathetic responses ${ }^{[40]}$. According to Foley TM and Digital Health Survey, reimbursement and state licensing requirements were other significant challenges ${ }^{[4]}$. Health facilities Accreditation Programme of America (HFAP) states that a health professional should be licensed in both states, where the practitioner resides and the other where the patient is living ${ }^{[42]}$. According to the guidelines laid down by the Board of Governors in partnership with NITI AYOG of India in March 2020, imposters can represent real patients. In video consults, there is a possibility of abuse/misuse of patients' privacy. In asynchronous communication such as emails, there will be delays in opinion ${ }^{[13]}$. If a doctor needs a physical examination to reach a diagnosis, TM is not enough. Prescribing medicines on telecommunication without examining the patient may invite chances of error. Furthermore, TM is technology-driven, and any breach in technology can lead to loss of patient's privacy and confidentiality ${ }^{[43]}$.

\section{Conclusion}

TM has become an essential tool in this pandemic due to COVID-19, limiting the transmission among patients and healthcare workers. Disasters and pandemics pose challenges to healthcare delivery, but TM will not solve them all but will be of some help. Even in normal circumstances, TM can reduce unnecessary visits to hospitals like in follow-ups and continuation of treatment. It should be included in the health care delivery infrastructure with all guidelines and legality to help the existing system and take over in times of need. However, training healthcare workers to use the digital platform effectively is the prerequisite of a smooth and successful experience and delivery of care in demanding circumstances.

\section{Author Contributions:}

Somprakas Basu was involved in the conceptual design and revising the article critically, Farhanul Huda was involved in revising the article critically and literature search and Praveen Kumar was involved in acquisition of data, drafting the article and literature search. All the authors approved the final version of the article before submission. 


\section{REFERENCES}

[1] Portnoy, J., Waller, M., \& Elliott, T. (2020). Telemedicine in the Era of COVID-19. The journal of allergy and clinical immunology. In practice, 8(5), 1489-1491. https://doi.org/10.1016/j.jaip.2020.03.008

[2] Liu, J., Liao, X., Qian, S., Yuan, J., Wang, F., Liu, Y., Wang, Z., Wang, F. S., Liu, L. \& Zhang, Z. (2020). Community Transmission of Severe Acute Respiratory Syndrome Coronavirus 2, Shenzhen, China, 2020. Emerging infectious diseases, 26(6), 1320-1323. https://doi.org/10.3201/eid2606.200239

[3] Wang, D., Hu, B., Hu, C., Zhu, F., Liu, X., Zhang, J., Wang, B., Xiang, H., Cheng, Z., Xiong, Y., Zhao, Y., Li, Y., Wang, X., \& Peng, Z. (2020). Clinical Characteristics of 138 Hospitalized Patients With 2019 Novel CoronavirusInfected Pneumonia in Wuhan, China. JAMA, 323(11), 1061-1069. https://doi.org/10.1001/jama.2020.1585

[4] Greenhalgh, T., Wherton, J., Shaw, S., \& Morrison, C. (2020). Video consultations for covid-19. BMJ (Clinical research ed.), 368, m998. https://doi.org/10.1136/bmj.m998

[5] Iacobucci G. (2019). NHS long term plan: Care to be shifted away from hospitals in "21 st century" service model. BMJ (Clinical research ed.), 364, 185. https://doi.org/10.1136/bmj.185

[6] Ohannessian, R., Duong, T. A., \& Odone, A. (2020). Global Telemedicine Implementation and Integration Within Health Systems to Fight the COVID-19 Pandemic: A Call to Action. JMIR public health and surveillance, 6(2), el8810. https://doi.org/10.2196/18810

[7] WHO Global Observatory for eHealth. (2010). TM: opportunities and developments in Member States: report on the second global survey on eHealth. World Health Organization. https://apps.who.int /iris/handle/10665/44497

[8] The impact of COVID-19 on health tech adoption in UK. https://www.hea lthcareitnews.com/news/europe/impact-covid-19-health-tech-adoption-uk

[9] Hollander, J. E., \& Carr, B. G. (2020). Virtually Perfect? Telemedicine for Covid19. The New England journal of medicine, 382(18), 1679-1681. https://doi.org/10.1056/NEJMp2003539

[10] Dorsey, E. R., \& Topol, E. J. (2020). Telemedicine 2020 and the next decade. Lancet (London, England), 395(10227), 859. https://doi.org/10.1016/S01406736(20)30424-4

[11] Smith, A. C., Thomas, E., Snoswell, C. L., Haydon, H., Mehrotra, A., Clemensen, J., \& Caffery, L. J. (2020). Telehealth for global emergencies: Implications for coronavirus disease 2019 (COVID-19). Journal of telemedicine and telecare, 26(5), 309-313. https://doi.org/10.1177/ 1357633X2 0916567

[12] Omboni, S. (2020). Telemedicine During The COVID-19 in Italy: A Missed Opportunity? Telemedicine and e-Health. doi:10.1089/tmj.2020.0106

[13] TMPractice Guidelines https://www.mohfw.gov.in/pdf/TM.pdf

[14] Krupinski, E. A., Antoniotti, N., \& Bernard, J. (2013). Utilization of the American Telemedicine Association's clinical practice guidelines. Telemedicine journal and e-health : the official journal of the American Telemedicine Association, 19(11), 846-851. https://doi.org/10.1089/tmj.2013.0027

[15] Raposo V. L. (2016). Telemedicine: The legal framework (or the lack of it) in Europe. GMS health technology assessment, 12, Doc03. https://doi.org $/ 10.3205 / \mathrm{hta} 000126$

[16] ATA letter to Congress on Coronavirus IV Legislation https://www .americantelemed.org/policies/ata-letter-to-congress-on-coronavirus-ivlegislation/

[17] Chauhan, V., Galwankar, S., Arquilla, B., Garg, M., Somma, S. D., El-Menyar, A., Krishnan, V., Gerber, J., Holland, R., \& Stawicki, S. P. (2020). Novel Coronavirus (COVID-19): Leveraging Telemedicine to Optimize Care While Minimizing Exposures and Viral Transmission. Journal of emergencies, trauma, and shock, 13(1), 20-24. https://doi.org/10.4103/JETS.JETS_32_20

[18] Telehealth during COIVD 19: New rules and considerations. https:/www.mondaq.com/unitedstates/healthcare/922532/telehealthduring-covid-19-new-rules-and-considerations

[19] Direct Access Testing(DAT) and Clinical Lab improvement Amendment(CLIA) https://www.cms.gov/Regulations-and-Guidance/Legislation /CLIA/Downloads/directaccesstesting.pdf

[20] PUBLIC LAW 110-425-OCTOBER 15, 2008 https://www. congress .gov /110/plaws/publ425/PLAW-110publ425.pdf

[21] Drug Enforcement Administration https://en.wikipedia.org/wiki /Drug_Enforcement_Administration

[22] Kannarkat, J. T., Smith, N. N., \& McLeod-Bryant, S. A. (2020). Mobilization of Telepsychiatry in Response to COVID-19-Moving Toward 21 st Century Access to Care. Administration and policy in mental health, 47(4), 489-491. https://doi.org/10.1007/s10488-020-01044-z

[23] OIG Policy Statement Regarding Physicians and Other Practitioners That Reduce or Waive Amounts Owed by Federal Health Care Program Beneficiaries for Telehealth Services During the 2019 Novel Coronavirus (COVID-19) Outbreak

https:/oig.hhs.gov/fraud/docs/alertsandbulletins/2020/policy-telehealth2020.pdf

[24] HIPAA waivers and compliance in COVID-19 pandemic https://www. agg.com/news-insights/publications/hipaa-waivers-and-compliance-incovid-19-pandemic/

[25] Cai, H., Wang, H., Guo, T., \& Bao, G. (2016). Application of Telemedicine in Gansu Province of China. PloS one, 11(6), e0158026. https://doi.org/10 .1371/journal.pone.0158026

[26] Cervino, G., \& Oteri, G. (2020). COVID-19 Pandemic and Telephone Triage before Attending Medical Office: Problem or Opportunity?. Medicina (Kaunas, Lithuania), 56(5), 250. https://doi.org/10.3390/medicina56050250

[27] Langabeer, J. R., II, M. G., Alqusairi, D., Champagne-Langabeer, T., Jackson, A., Mikhail, J., \& Persse, D. (2016). Telehealth-enabled emergency medical services program reduces ambulance transport to urban emergency departments. Western journal of emergency medicine, 17(6), 713.

[28] Zhang, J., Zhou, L., Yang, Y., Peng, W., Wang, W., \& Chen, X. (2020). Therapeutic and triage strategies for 2019 novel coronavirus disease in fever clinics. The Lancet. Respiratory medicine, 8(3), ell-el2. https:// doi.org/ 10.1016/S2213-2600(20)30071-0
[29] Home care for patients with COVID-19 presenting with mild symptoms and management of their contacts. https://www.who.int/ publications i/item/home-care-for-patients-with-suspected-novel-coronavirus-(ncov)infection-presenting-with-mild-symptoms-and-management-of-contacts

[30] Bashshur, R. L., Shannon, G. W., Smith, B. R., Alverson, D. C., Antoniotti, N. Barsan, W. G., Bashshur, N., Brown, E. M., Coye, M. J., Doarn, C. R., Ferguson, S., Grigsby, J., Krupinski, E. A., Kvedar, J. C., Linkous, J., Merrell, R. C., Nesbitt T., Poropatich, R., Rheuban, K. S., Sanders, J. H., ... Yellowlees, P. (2014). The empirical foundations of telemedicine interventions for chronic disease management. Telemedicine journal and e-health : the official journal of the American Telemedicine Association, 20(9), 769-800. https://doi.org/10.1089/tmj.2014.9981

[31] Flodgren, G., Rachas, A., Farmer, A. J., Inzitari, M., \& Shepperd, S. (2015). Interactive telemedicine: effects on professional practice and health care outcomes. The Cochrane database of systematic reviews, 2015(9), CD002098. https://doi.org/10.1002/14651858.CD002098.pub2

[32] Mukundan, S., Jr, Vydareny, K., Vassallo, D. J., Irving, S., \& Ogaoga, D. (2003). Trial telemedicine system for supporting medical students on elective in the developing world. Academic radiology, 10(7), 794-797. https:// doi.org/10.1016/s1076-6332(03)80125-3

[33] Ali, S. R., Dobbs, T. D., \& Whitaker, I. S. (2020). Webinars in plastic and reconstructive surgery training - a review of the current landscape during the COVID-19 pandemic. Journal of plastic, reconstructive \& aesthetic surgery : JPRAS, 73(7), 1357-1404. https://doi.org/10.1016/j.bjps.2020.05.038

[34] Online course for surgeons/e-surgery. https://www.eintegrity.org/e-learninghealthcare-course/surgery.html

[35] Deaton, D. H., Balch, D. Kesler, C., Bogey, W. M., \& Powell, C. S. (1999) Telemedicine and endovascular aortic grafting. American journal of surgery, 177(1), 75-77. https://doi.org/10.1016/s0002-9610(98)00309-2

[36] Marckmann G. (2001). Teaching science vs. the apprentice model--do we really have the choice?. Medicine, health care, and philosophy, 4(1), 85-89. https://doi.org/10.1023/a:1009956310614

[37] Education in time of a pandemic: how to support teachers and students? https://www.eden-online.org/education-in-time-of-a-pandemic-how-tosupport-teachers-and-students/

[38] Terry, C., \& Cain, J. (2016). The Emerging Issue of Digital Empathy. American journal of pharmaceutical education, 80(4), 58. https://doi.org/10.56 $88 /$ ajpe80458

[39] Three ways to add empathy to TM. https://insights.patientbond.com/blog/3ways-to-add-empathy-to-TM\#: :text=Listen,to\%20share $\% 2 \mathrm{C} \% 20$ th e y $\%$ 20 feel\%20respected.

[40] Ranjan, P., Kumari, A., \& Chakrawarty, A. (2015). How can Doctors Improve their Communication Skills?. Journal of clinical and diagnostic research : JCDR, 9(3), JE01-JE4. https://doi.org/10.7860/JCDR/2015/12072.5712

[41] 2017 TM and Digital health survey https://www.foley .com /en/in sights/publications/2017/11/2017-TM--digital-health-survey

[42] Busey, J. C., \& Michael, P. (2008). Telehealth--opportunities and pitfalls. Journal of the American Dietetic Association, 108(8), 1296-1301. https://doi.org/10.1016/j.jada.2008.05.002

[43] Krasniansky A. Telehealth amid COVID-19: What health care providers should know. https://blog.petrieflom.law.harvard.edu/2020/04/02/telehealthamid-covid-19-what-health-care-providers-should-know/ 